\title{
Inhalt (nach Abschnitten)
}

\begin{tabular}{|c|c|c|}
\hline & & Seite \\
\hline & erzeichnis (Aufgliederung der Abschnitte). & 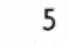 \\
\hline & 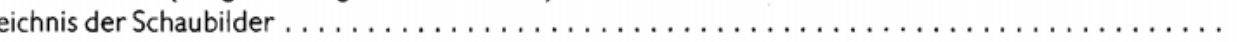 & 16 \\
\hline & eine Vorbemerkungen, Abkürzungen und Zeichenerklärung $\ldots \ldots \ldots \ldots \ldots \ldots \ldots$ & 17 \\
\hline 1 & Geographische und meteorologische Angaben, Naturschutz $\ldots \ldots \ldots \ldots \ldots \ldots \ldots$ & 20 \\
\hline 2 & 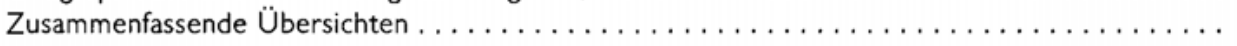 & 31 \\
\hline 3 & 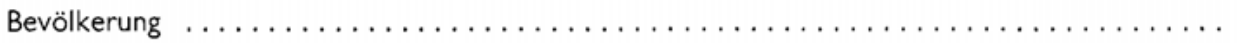 & 50 \\
\hline 4 & $\ldots \ldots \ldots \ldots \ldots \ldots \ldots \ldots \ldots \ldots \ldots \ldots \ldots \ldots \ldots \ldots \ldots \ldots \ldots \ldots \ldots$ & 85 \\
\hline 5 & 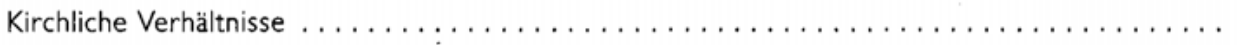 & 94 \\
\hline 6 & 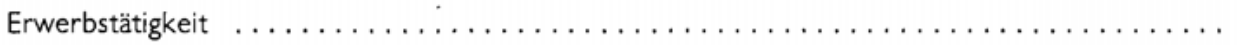 & 97 \\
\hline 7 & 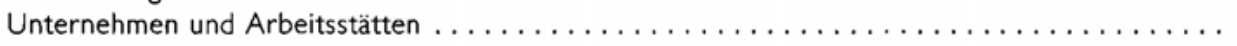 & 115 \\
\hline 8 & 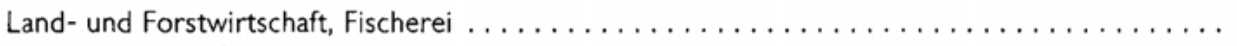 & 140 \\
\hline 9 & 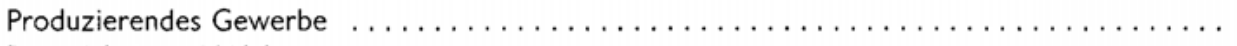 & 165 \\
\hline 10 & 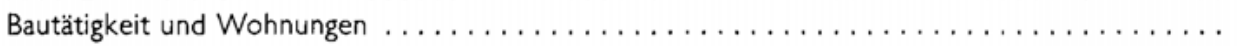 & 215 \\
\hline 11 & 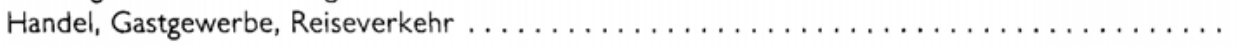 & 227 \\
\hline 12 & 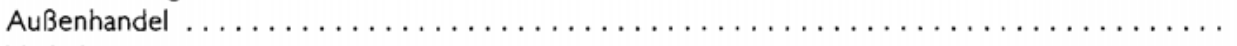 & 256 \\
\hline 13 & $\ldots \ldots \ldots \ldots \ldots \ldots \ldots \ldots \ldots \ldots \ldots \ldots \ldots \ldots \ldots \ldots \ldots \ldots$ & 285 \\
\hline 14 & 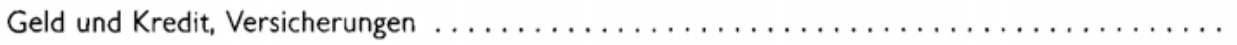 & 317 \\
\hline 15 & 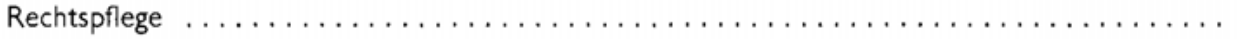 & 335 \\
\hline 16 & 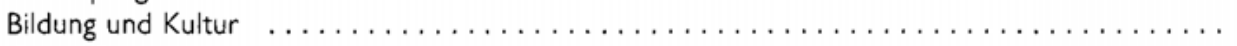 & 352 \\
\hline 17 & 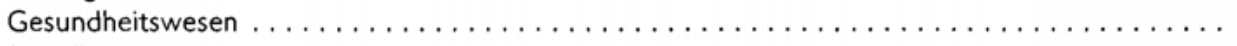 & 391 \\
\hline 18 & 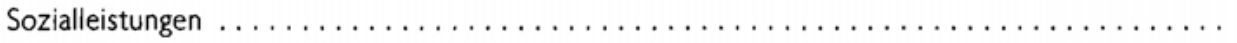 & 403 \\
\hline 19 & 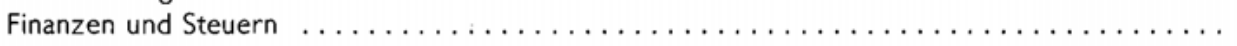 & 426 \\
\hline 20 & 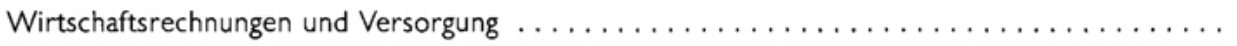 & 464 \\
\hline 21 & 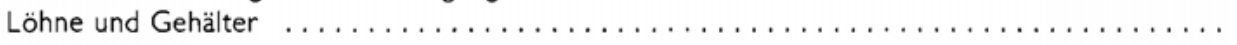 & 480 \\
\hline 22 & $\ldots \ldots \ldots \ldots \ldots \ldots \ldots \ldots \ldots \ldots \ldots \ldots \ldots \ldots \ldots \ldots \ldots \ldots \ldots \ldots \ldots$ & 500 \\
\hline 23 & 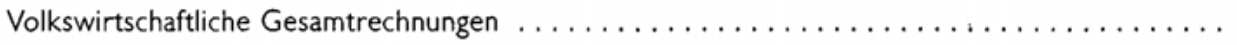 & 537 \\
\hline 24 & 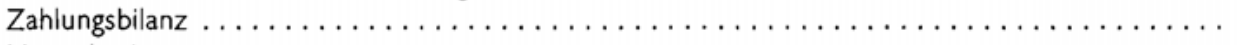 & 570 \\
\hline 25 & $\ldots \ldots \ldots \ldots \ldots \ldots \ldots \ldots$ & 580 \\
\hline 26 & 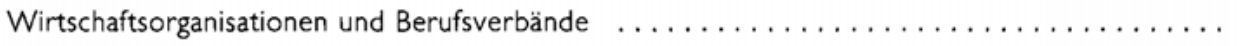 & 593 \\
\hline & Republik und Berlin (Ost) & 601 \\
\hline & 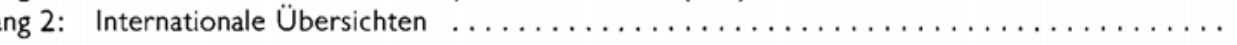 & 635 \\
\hline & hachweis & 747 \\
\hline & jister & 771 \\
\hline
\end{tabular}

